\title{
Comparison of Cortico-Cortical and Cortico-Collicular Signals for the Generation of Saccadic Eye Movements
}

\author{
STEFANO FERRAINA, MARTIN PARÉ, AND ROBERT H. WURTZ \\ Laboratory of Sensorimotor Research, National Eye Institute, National Institutes of Health, Bethesda, Maryland 20892
}

Received 19 April 2001; accepted in final form 17 October 2001

Ferraina, Stefano, Martin Paré, and Robert H. Wurtz. Comparison of cortico-cortical and cortico-collicular signals for the generation of saccadic eye movements. J Neurophysiol 87: 845-858, 2002; 10.1152/ jn.00317.2001. Many neurons in the frontal eye field (FEF) and lateral intraparietal (LIP) areas of cerebral cortex are active during the visualmotor events preceding the initiation of saccadic eye movements: they respond to visual targets, increase their activity before saccades, and maintain their activity during intervening delay periods. Previous experiments have shown that the output neurons from both LIP and FEF convey the full range of these activities to the superior colliculus (SC) in the brain stem. These areas of cerebral cortex also have strong interconnections, but what signals they convey remains unknown. To determine what these cortico-cortical signals are, we identified the LIP neurons that project to FEF by antidromic activation, and we studied their activity during a delayed-saccade task. We then compared these cortico-cortical signals to those sent subcortically by also identifying the LIP neurons that project to the intermediate layers of the SC. Of 329 FEF projection neurons and $120 \mathrm{SC}$ projection neurons, none were co-activated by both FEF and SC stimulation. FEF projection neurons were encountered more superficially in LIP than SC projection neurons, which is consistent with the anatomical projection of many cortical layer III neurons to other cortical areas and of layer $\mathrm{V}$ neurons to subcortical structures. The estimated conduction velocities of FEF projection neurons $(16.7 \mathrm{~m} / \mathrm{s})$ were significantly slower that those of SC projection neurons $(21.7 \mathrm{~m} / \mathrm{s})$, indicating that FEF projection neurons have smaller axons. We identified three main differences in the discharge properties of FEF and SC projection neurons: only $44 \%$ of the FEF projection neurons changed their activity during the delayed-saccade task compared with $69 \%$ of the SC projection neurons; only $17 \%$ of the task-related FEF projection neurons showed saccadic activity, whereas $42 \%$ of the SC projection neurons showed such increases; $78 \%$ of the FEF projection neurons had a visual response but no saccadic activity, whereas only $55 \%$ of the SC projection neurons had similar activity. The FEF and SC projection neurons had three similarities: both had visual, delay, and saccadic activity, both had stronger delay and saccadic activity with visually guided than with memory-guided saccades, and both had broadly tuned responses for disparity stimuli, suggesting that their visual receptive fields have a three-dimensional configuration. These observations indicate that the activity carried between parietal and frontal cortical areas conveys a spectrum of signals but that the preponderance of activity conveyed might be more closely related to earlier visual processing than to the later saccadic stages that are directed to the SC.

\section{N T R O D U C T I O N}

Neural processing by the brain, whether for perception or for action, involves a series of distinct structures organized into

\footnotetext{
Address for reprint requests: R. H. Wurtz, Laboratory of Sensorimotor Research, National Eye Institute, National Institutes of Health, 9000 Rockville Pike, Bldg. 49, Rm. 2A50, Bethesda, MD 20892-4435 (E-mail: bob@1sr.nei.nih.gov).
}

specialized circuits. In the primate brain, a number of possible circuits are known, and the activity of neurons at different nodes along these circuits have been investigated, but our knowledge of the functional organization of these circuits is based largely on knowledge of their anatomical connections rather than on their functional links. Several recent attempts have been made to delineate the sequence of processing at successive stages underlying relatively simple behaviors such as the evolution of a decision based on a visual discrimination (Horwitz and Newsome 1999; Kim and Shadlen 1999; Shadlen and Newsome 1996), working memory (Chafee and GoldmanRakic 1998, 2000), and the generation of rapid or saccadic eye movements (Paré and Wurtz 1997, 2001; Sommer and Wurtz 2000, 2001).

In the study of saccadic eye movements, one approach has been to determine what signals are conveyed from one region to another as the first step in determining the underlying neuronal circuits. In a recent set of experiments on the lateral intraparietal (LIP) (Paré and Wurtz 1997, 2001) and the frontal eye field (FEF) (Sommer and Wurtz 2000, 2001) areas of cerebral cortex, the same behavioral tasks were used across experiments so that the outputs of the two areas could be compared (Wurtz et al. 2001). LIP and FEF were examined because neurons in both areas change their activity throughout the sequence of saccade generation from target onset to saccade initiation: the activity changes in response to the presentation of a visual target and frequently increases before saccade onset (for reviews, see Andersen et al. 1997; Colby and Goldberg 1999; Schall 1997). Activity often continues during any delay period between target onset and saccade generation, and activity in this period is of particular interest because it may represent the intervening neuronal steps between the sensory input and the motor output. Furthermore, artificially activating these areas by electrical stimulation generates saccades (Bruce et al. 1985; Keating et al. 1983; Kurylo and Skavenski 1991; Robinson and Fuchs 1969; Shibutani et al. 1984; Thier and Andersen 1998), and reversible inactivation impairs their generation (Dias and Segraves 1999; Li et al. 1999; Schiller et al. 1987; Sommer and Tehovnik 1997). The combination of neuronal activity, stimulation, and inactivation indicates that FEF and LIP have a special relation to the generation of saccades. We also know that both areas also have strong projections to the intermediate layers of the superior colliculus (SC) on the

The costs of publication of this article were defrayed in part by the payment of page charges. The article must therefore be hereby marked "advertisement" in accordance with 18 U.S.C. Section 1734 solely to indicate this fact. 
roof of the brain stem (Andersen et al. 1990; Lynch et al. 1985; Schall et al. 1995), and it is well known that the SC is also related to the generation of saccades (Sparks and HartwichYoung 1989).

Knowing this target structure of FEF and LIP has enabled the identification of the output neurons of these two cortical areas (Paré and Wurtz 1997, 2001; Segraves and Goldberg 1987; Sommer and Wurtz 2000, 2001). The output neurons from both LIP and FEF to SC were found to convey information not only on the impending movement but also on the visual target and the delay activity as well; they did not represent a single end point of cortical processing that was related just to saccade generation. Because the activity of the neurons in the target structure (SC) of these output neurons was also known, this comparison could be carried a step farther, by comparing the activity of the output neurons to those in the next structure (Paré and Wurtz 2001; Wurtz et al. 2001). Such a comparison showed that there was an overlap in the functions represented in the cortical areas and the $\mathrm{SC}$, but a quantitative comparison showed a shift in the magnitude of the activity from more visually related in the cortical output to more saccade related in the SC (Paré and Wurtz 2001). Thus while there was an overlap in the types of neuronal activity seen in cortex and colliculus, there was also a quantitative shift in the nature of that activity.

What remains unknown, however, is the interaction within the cortex before activity is conveyed from either of these two cortical areas to the SC. This is particularly relevant to LIP and FEF because they have strong anatomical connections between them (Andersen et al. 1985, 1990; Barbas and Mesulam 1981; Blatt et al. 1990; Huerta et al. 1987; Kunzle and Akert 1977; Petrides and Pandya 1984; Schall et al. 1995; Selemon and Goldman-Rakic 1988; Stanton et al. 1995; Tian and Lynch 1996). A study of such cortico-cortical connections would also provide the first information in the oculomotor system of the signals directed from one cortical area to another cortical area. Furthermore, because we already know the signals that go from cortex to SC, if we could now determine what passes between the cortical areas, we could compare the signals descending from the cerebral cortex to those transmitted across the cortex.

In the present study we made such a comparison by identifying both the LIP neurons that project cortically by antidromically activating them from FEF with electrical stimulation and the LIP neurons that project to the brain stem by antidromically activating them from the SC (Fig. 1A). In microelectrode penetrations through LIP, we examined each neuron for its connection to both FEF and SC and then determined its visual, delay, and saccade-related activity in saccade tasks. We required the monkey to make saccades to targets that had to be remembered as well as to visual targets still present to determine how much the delay activity was dependent on the presence of the visual stimulus. We found that the projection to FEF and SC was from two separate sets of neurons, and where penetrations cut across cortical layers, we found that the FEF projection neurons were usually located more superficially in the cortex than the SC projection neurons. But the information conveyed by the FEF and SC projection neurons was not so completely separated; visual, delay, and saccadic activities were present in both projections. The information in the two projections, however, was not identical in our sample of antidromically activated neurons; the LIP neurons projecting to

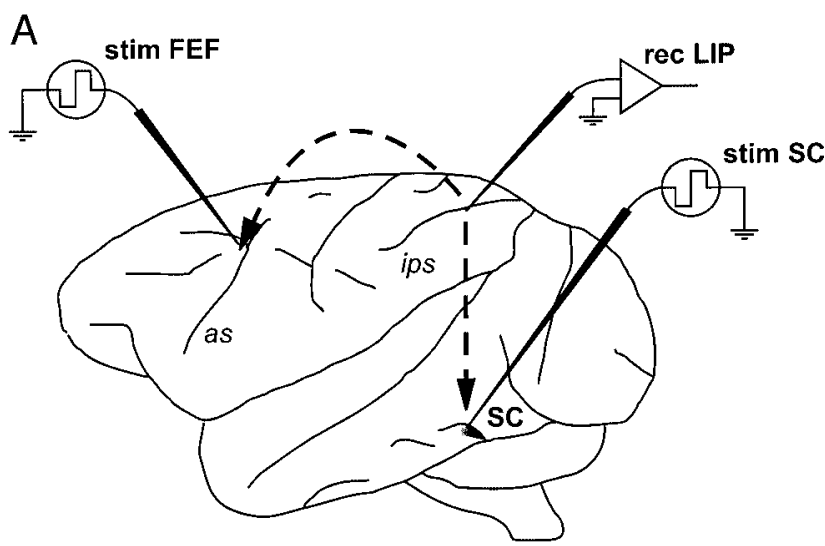

B DELAYED SACCADE TASK

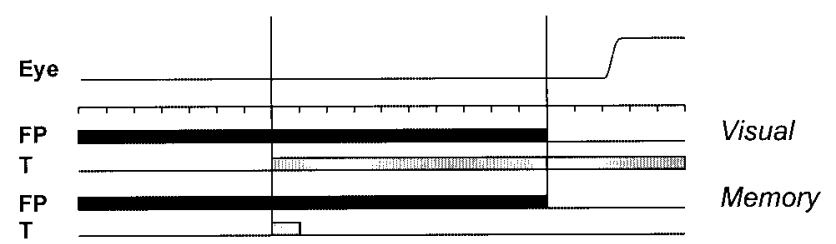

FIG. 1. Schematic of experimental procedures and behavioral paradigms. $A$ : comparison of the lateral intraparietal (LIP) projections to frontal eye field (FEF) and to superior colliculus (SC). Schematic location of stimulating and recording electrodes. Each neuron successfully isolated in LIP was tested for antidromic activation by stimulation in both FEF and SC. B: schematic representations of the delayed-saccade task employed in this study. The eye position (E) and the presentation of the visual stimuli (central fixation point, FP; eccentric saccade target, T) are shown as a function of time. The visual stimulus was presented either for a brief interval (memory trials) or until the end of the trial (visual trials), respectively. See METHODS for further details.

FEF had activity that was less related to saccade generation than did those projecting to SC and they were more dependent on the presence of the visual stimuli than were those projecting to the SC. Thus while both the cortical and subcortical projections contain a spectrum of activity related to all phases of behavior, the activity between cortical areas tended to be skewed toward visual processing. Taken together, these results suggest that neuronal activity in LIP, FEF and SC is more compatible with a distributed system than with discrete sequential processing.

A brief report has appeared previously (Ferraina et al. 1999).

\section{METHODS}

\section{Physiological and behavioral procedures}

Two male monkeys (Macaca mulatta, referred to as monkey $A$ and $C)$ were studied using procedures identical to those recently described (Paré and Wurtz 1997, 2001; Sommer and Wurtz 2000, 2001). Only the methods specific to the present experiments will be described. All animal care and experimental procedures were approved by the Institute Animal Care and Use Committee and complied with Public Health Service Policy on the humane care and use of laboratory animals.

To position the recording cylinders (Fig. 1A), we used stereotaxic coordinates and magnetic resonance imaging (MRI) of each monkey's brain. Following the surgery and before the beginning of the experiments, a second MRI was performed with at least one reference electrode fixed to a penetration-guidance grid (Crist et al. 1988) in each of the cylinders. These images were used to provide an anatom- 
ical reference for the orientations of the penetrations within the brain regions accessible by the cylinders. In each monkey, one cylinder was centered on stereotaxic coordinates P5.0-L12.0 mm at an angle of $30^{\circ}$ from vertical to allow recordings from area LIP; a second cylinder was placed flat on the skull at A25-L24 mm to access the FEF; a third cylinder was directed toward the $\mathrm{SC}(15 \mathrm{~mm}$ above and $1 \mathrm{~mm}$ posterior of stereotaxic 0 ) and was centered on the midline with its top tilted $42^{\circ}$ posterior of vertical.

During the experiments, the monkey sat in a primate chair with its head restrained and faced a tangent screen $57 \mathrm{~cm}$ in front of it. All tasks were performed in dim ambient light with visual stimuli generated by a video projector (Sharp model 850) back-projected onto the translucent screen.

We initially identified LIP neurons using a delayed-saccade task (Fig. $1 B$ ). Each trial started with the appearance of a central fixation point and, after $500-800 \mathrm{~ms}$ of fixation, a peripheral visual target $\left(<0.5^{\circ}\right.$ diam spot $)$ appeared in the center of the neuron's receptive field and remained on only briefly (100-ms memory trials) or until the end of the trial (visual trials). After a 600- to 1,100-ms delay period following the onset of the peripheral stimulus, the monkey was required to make a saccade to the remembered location of the target (memory trials) or to the still visible target (visual trials) within 500 $\mathrm{ms}$ to obtain a liquid reward.

We then determined the visual sensitivity of each LIP neuron and estimated the size of its receptive field while the monkey fixated on a spot of light during the fixation period of the delayed-saccade task. The monkey was rewarded for maintaining steady fixation (1-1.5 s) within a computer-defined window $\left( \pm 1^{\circ}\right)$ centered on the fixation point in the middle of the screen. Spots of light $\left(1-5^{\circ}\right.$ in diameter $\sim 1$ $\log$ unit above background) were then projected onto the screen with a hand held projector (an ophthalmoscope) to determine the best visual stimulus and the location of the receptive field of the neuron. The best location for the target was then determined using the delayed-saccade task while moving the target on the screen in steps of $1^{\circ}$, but we did not determine the precise edges of the visual field. For neurons not responsive to such spots of light, we further tested them using the video projector to vary, size, luminance, color, and shape and motion of object stimuli.

In the course of this exploration of the visual sensitivity of the LIP neurons, we noticed that some neurons responded strongly to handheld objects located near the monkey's face; this suggested that some of these neurons might have three-dimensional receptive fields. Evidence for such a property has been previously presented for LIP neurons antidromically identified as projecting to SC (Gnadt and Beyer 1998) as well as from nonidentified LIP neurons (Gnadt and Mays 1995). We therefore examined the sensitivity of many of the LIP neurons activated from FEF and from SC to disparity stimuli. Disparity tests were done after a neuron had been tested in the delayed-saccade task if time allowed. For neurons that did not have a clear visual receptive field, the disparity stimuli were placed in the same part of the visual field where a receptive field was found for adjacent neurons.

To produce disparity stimuli, we divided the image projected onto the tangent screen into two halves and included a fixation point and an eccentric visual stimulus in each half of the image as described previously (Eifuku and Wurtz 1999). A base-out prism positioned in front of each eye deflected the line of sight of the right eye to the right and that of the left eye to the left. Retinal disparity was induced by changing the relative position of the visual stimuli displayed on the half screen, and to survey a broad range of disparity, it varied from -3 to $+3^{\circ}$ in $1^{\circ}$ steps. The different disparity values were presented in a random order with the zero-disparity stimuli positioned in the center of the neuron's visual field. In a fixation task, the disparity stimulus appeared after 500-800 ms of fixation and remained present for 1,000 $\mathrm{ms}$ at the location in the visual field that had elicited the optimal activation with zero disparity. The fixation point was always on the screen at $0^{\circ}$ disparity. Throughout the trial, the monkey maintained fixation with both eyes (as measured by eye coils implanted in each eye) within a computer-controlled window of $\pm 1-1.5^{\circ}$. Because of the optics of the prisms and the display arrangement in the disparity fixation task, we were limited to testing visual fields no more eccentric than $15^{\circ}$

\section{Neuronal identification}

Single neurons were recorded with tungsten microelectrodes (Frederick Haer, $1.0-2.0 \mathrm{M} \Omega$ at $1 \mathrm{kHz}$ ). We first identified the lateral bank of the intraparietal sulcus using the MRI of the monkey's brain. We then identified area LIP physiologically by the incidence of neurons with significant visual responses and saccade-related activity. Neurons were isolated while the monkey performed the delayed-saccade tasks, and LIP output neurons were identified antidromically by stimulation pulses delivered within the FEF and the SC (Fig. 1A). The FEF- and SC-stimulating electrodes were also tungsten electrodes (Frederick Haer, impedance of $50-100 \mathrm{k} \Omega$ at $1 \mathrm{kHz}$ ) and were used both to record and stimulate neurons throughout each penetration.

FEF-stimulating electrodes were directed toward the anterior bank of the arcuate sulcus, as seen on the MRI, and penetrations within the FEF itself were identified physiologically by the incidence of neurons with a visual response and saccade-related activity and by the ability to evoke saccades with stimulus trains of low intensity $(<50 \mu \mathrm{A}, 400$ $\mathrm{Hz}, 100 \mathrm{~ms}$ ). Each of these stimulating electrodes ( $\leq 3$ used successively during a single LIP penetration) was moved with a microdrive during each antidromic activation experiment. For antidromic stimulation, the stimuli were single biphasic pulses ( $0.15 \mathrm{~ms}$ per phase), and stimulus current was measured by taking the voltage across a $10-\mathrm{k} \Omega$ resistor in series with the stimulating electrode, with 500-600 $\mu \mathrm{A}$ used during search for antidromic activation. The threshold intensity to evoke antidromic responses was defined as the intensity that evoked a response on $\sim 50 \%$ of the stimulations. FEF stimulation produced antidromic activation in half of the LIP output neurons at threshold intensity $<650 \mu \mathrm{A}$ with a mean across the sample of $674 \pm 333 \mu \mathrm{A}$ (range 100-1,500).

SC-stimulating electrodes were positioned among saccade-related neurons within the intermediate layers after we had determined the layout of the SC map of movement fields using both single- and multiunit recording and low-intensity stimulation trains $(<10 \mu \mathrm{A}, 400$ $\mathrm{Hz}, 100 \mathrm{~ms}$ ). During antidromic activation experiments, SC stimulation electrodes were either moved with a microdrive during each session or held fixed chronically (by cementing the electrode and guide-tube to the grid with epoxy) at low-threshold stimulation depths and predetermined locations within the SC map. The electrical stimuli were the same as those used in the FEF. SC stimulation produced activation of half of the LIP output neurons at threshold intensity of $<400 \mu \mathrm{A}$ with a mean for all stimulation sites of $475 \pm 297 \mu \mathrm{A}$ (range 30-1,400).

The antidromic nature of the responses was ascertained first by their constant latency (black traces in Fig. $2 A$ ) with variability $<1 / 10$ of a millisecond that did not decrease appreciably with increasing stimulus intensity. That the stimulation-induced responses were antidromic was further verified using the collision test in which the stimulus was triggered by a spontaneously occurring action potential (gray traces in Fig. 2A). In the collision test, the evoked response was abolished when the delay between the spontaneous action potential and the electrical stimulus matched the collision interval, i.e., if it was equal or less than the neuron's response latency plus its axon's refractory period (Lemon 1984). Consistent failure of the collision test suggested that the activation was orthodromic and involved at least one synapse.

LIP neurons were included in our sample only if they were activated by stimulation of either the FEF or the SC. Neurons that we failed to activate antidromically were not included in our sample because we could not ascertain whether such neurons did or did not project to the FEF or SC; our failure to activate them could have been due to a spatial mismatch between their axonal terminals and the 
A
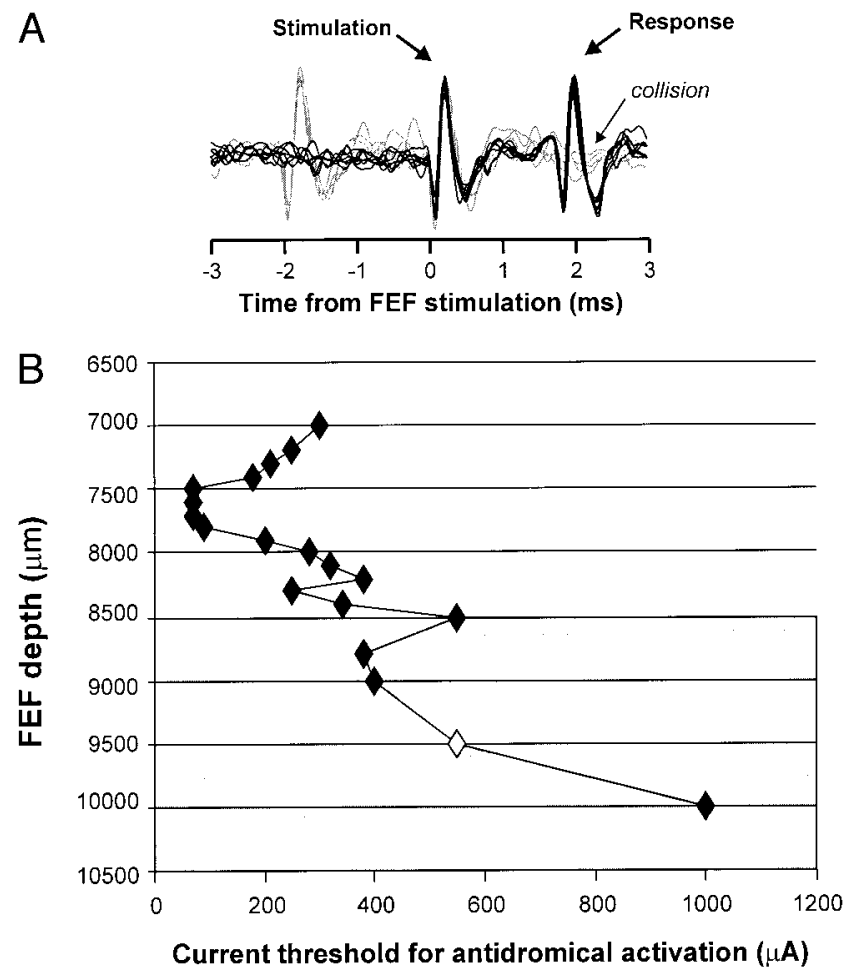

FIG. 2. Antidromic stimulation methods. A: waveforms of the action potentials of an LIP neuron following FEF stimulation. The gray waveforms were obtained during the collision test. $B$ : depth-threshold curve for a sample penetration through FEF. Current threshold required to antidromically activate an LIP neuron at different FEF depths within a single penetration. Gray area indicates region where it was possible to evoke saccades using trains of stimuli and currents $<150 \mu \mathrm{A}$. White diamond symbol indicates site of lowest threshold for evoking a saccade.

stimulating electrodes. The LIP projection neurons included in our sample were identified using two complementary methods. In general, as the recording electrode was advanced within area LIP, a neuron was identified because it had a fixed latency response to the periodic stimulation of FEF or SC (at 500-600 $\mu \mathrm{A}$ used for searching). The neuron was then isolated by moving the recording electrode to maximize the amplitude of the antidromic responses. Alternatively, a neuron was first identified as the electrode was advanced and then was tested for antidromic activation. In this case, if the activation failed, we increased the stimulation current and gradually moved the stimulating electrodes to verify whether there was a more effective site within the current FEF and SC tracks.

For antidromic activation of LIP neurons from SC and FEF, we tried to place the stimulating electrodes in the region that represented a similar eccentricity and location in the visual quadrant as the LIP neurons (Paré and Wurtz 1997). For the LIP neurons, we used their visual and movement fields to locate the region of the visual field to which they were related. For the SC and FEF, we determined the part of the field related to the stimulation site by applying trains of stimulation pulses and noting the termination of the resulting evoked saccades. This worked well for the SC but not for the FEF, and Fig. $2 B$ illustrates the problem in FEF. In this sample penetration, the lowest threshold for antidromically activating LIP neurons (abscissa in Fig. $2 B$ ) was near the top of the penetration (ordinate in Fig. $2 B$ ), but the lowest threshold for evoking saccades was in the depth of the penetration (shaded area in Fig. $2 B$ ). Furthermore, the directions of saccades evoked at the point of lowest threshold for LIP antidromic stimulation and the point of lowest threshold for stimulation evoked saccades were slightly different. We assume that this difference arises because the terminals of LIP output neurons projecting to FEF (Andersen et al. 1990) contact layers distant from those layers con- taining the subcortical output neurons. Because our penetrations were never perfectly orthogonal to the cortical layers, the part of the visual field shifted somewhat as the electrode advanced from the lowest threshold for antidromic stimulation to the lowest threshold for evoking saccades. We therefore stimulated FEF at the point of lowest antidromic stimulation threshold not at the point that best aligned evoked saccades with the movement fields of the LIP neurons.

\section{Data analysis}

Rasters of neuronal discharges and continuously varying spike density functions (MacPherson and Aldridge 1979; Richmond et al. 1987) were aligned on specific events in the paradigms. To generate the spike density function, a Gaussian pulse was substituted for each spike, and then all Gaussians were summed together to produce a function continuous in time.

Using the raw spike counts, we measured the level of neuronal activity during successive epochs of the behavioral tasks. In the delayed-saccade task, the fixation activity was determined by the mean discharge rate during a 300-ms epoch of the fixation period, from 500 to $200 \mathrm{~ms}$ before the target presentation. The visual activity was determined as the mean discharge rate during a 50-ms interval starting at the onset of the visual response latency, estimated by visual inspection using a high-resolution spike density function $(\sigma=1 \mathrm{~ms})$. If a neuron showed no increase in activity within $200 \mathrm{~ms}$ after the visual stimulus onset, its level of activity was measured during a 50 -ms interval starting $50 \mathrm{~ms}$ from the stimulus onset. The delay activity was the mean discharge rate in the last $300 \mathrm{~ms}$ of the delay epoch, ending when the fixation point disappeared. The presaccadic activity was the mean discharge rate in the $100 \mathrm{~ms}$ before saccade initiation. Visual and delay activity were regarded as significant if they differed statistically from the fixation activity, and saccadic activity was considered significant if it was statistically greater than delay activity.

We performed a Shapiro-Wilk test of normality on each data set. Between-sample comparisons (those between visual and memory trials) used either the unpaired Student's $t$-tests or nonparametric Mann-Whitney $U$ tests, depending on the sample normality. Withinsample comparisons (those among visual, delay, or saccadic activity within visual or memory trials) used either paired Student's $t$-tests or nonparametric Wilcoxon signed-rank tests. For group comparisons, we used either an ANOVA or the nonparametric Kruskal-Wallis ANOVA. Post hoc comparisons were conducted with the Tukey's honestly significant difference test (HSD) method. Significance was set at $P<0.01$, except for the multiple pairwise comparison $(P<$ $0.05)$.

\section{R E S U L T S}

\section{Antidromic activation}

A total of 329 LIP neurons were antidromically activated by FEF stimulation, and 120 neurons by SC stimulation. The action potentials produced by each of these neurons in response to the electrical stimulation had a fixed latency, and the collision test was applied to all those that we could unmistakably isolate. Results from 160 neurons activated from FEF and 79 neurons activated from SC always revealed that these stimulation-induced responses collided with self-generated action potentials as would be expected from antidromic activation.

Figure $3 A$ shows the latency distribution of the antidromic responses of each of the activated neurons. For the neurons antidromically activated from FEF (LIPfef neurons), the latencies ranged from 0.5 to $8.0 \mathrm{~ms}$ with a mean of $2.3 \pm 1.3$ (SD) $\mathrm{ms}$, and for those activated from SC (LIPsc neurons), the 

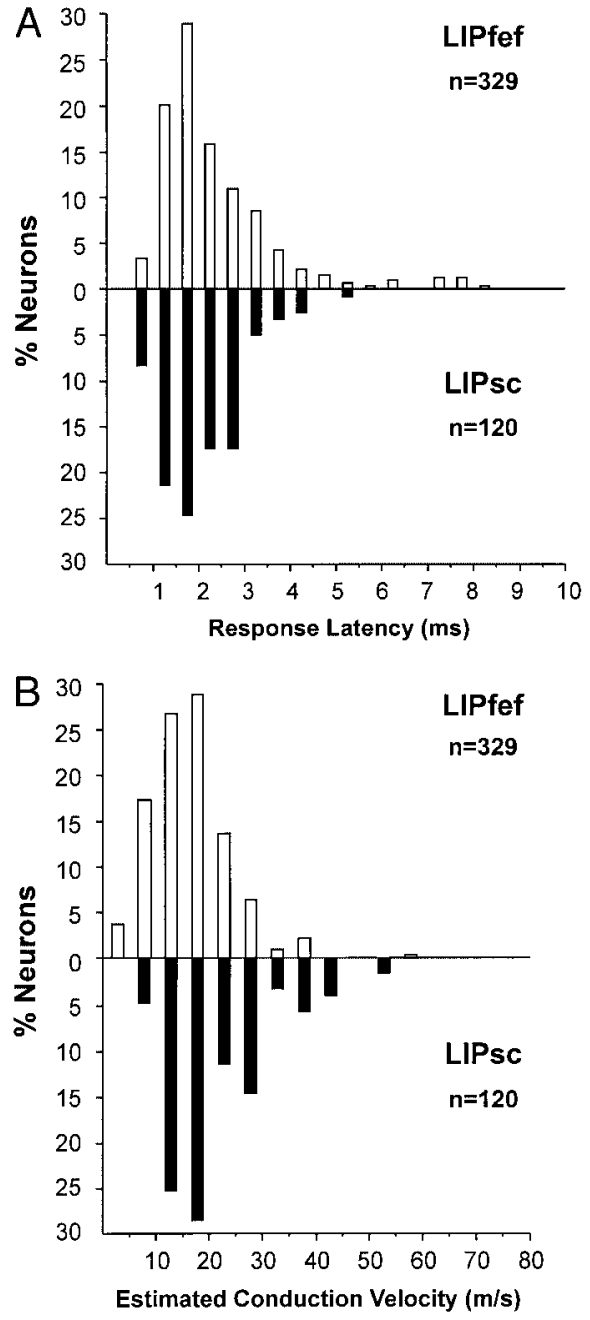

FIG. 3. Antidromic latency $(A)$ and conduction velocity $(B)$ of all LIP neurons antidromically activated by stimulation of FEF and SC. The latency of the antidromic responses is the interval from the onset of the electrical stimulus (at 1.2 times threshold intensity) to the onset of the evoked action potentials; no allowance was made for activation time (Lemon 1984). For conduction velocity, the distance from LIP to FEF was taken as $30 \mathrm{~mm}$ and from LIP to $\mathrm{SC}$ as $36 \mathrm{~mm}$. We made no adjustment in this distance to allow for differing locations in depth or anterior-posterior position in LIP of the individual neurons. In this and subsequent figures, LIPfef indicates LIP neurons antidromically activated from FEF, and LIPsc indicates LIP neurons activated from SC. The mean conduction velocity calculated only for the neurons that passed the collision test was $18.3 \mathrm{~m} / \mathrm{s}$ for the LIPfef neurons (160 neurons) and $23.2 \mathrm{~m} / \mathrm{s}$ for the LIPsc neurons (79 neurons). This difference was statistically significant (Mann-Whitney rank sum test; $P<0.001$ ).

latencies varied between 0.7 and $5.2 \mathrm{~ms}$ with a mean of $2.0 \pm$ 0.8 (SD) ms.

Figure $3 B$ shows the conduction velocities of the LIPfef and LIPsc neurons derived from the response latencies and anatomical distances estimated from the cylinder's stereotaxic coordinates, the monkey's MRI, and guidance from standard atlases. Assuming the shortest white-matter route for the cortico-cortical projection and an initial route parallel to the intraparietal sulcus followed by a deviation through the posterior limb of the internal capsule for the cortico-tectal projection (G. Stanton, personal communication), we estimated the average distance from LIP to FEF to be $30 \mathrm{~mm}$ and that from LIP to $\mathrm{SC}$ to be $36 \mathrm{~mm}$. As a consequence, the mean conduction velocity for LIPfef neurons was $16.7 \mathrm{~m} / \mathrm{s}$ and for LIPsc neu- rons was $21.7 \mathrm{~m} / \mathrm{s}$. This difference was statistically significant (Mann-Whitney rank sum test; $P<0.001$ ), implying that the LIP neurons projecting to FEF have axons of smaller diameters and, as a consequence, possibly smaller cell bodies, than those projecting to the SC.

\section{Segregation of LIPfef and LIPsc neurons}

In a series of penetrations through LIP in each of the two monkeys, we first determined whether or not there was any order in which the neurons were activated from the FEF and SC. For monkey $C$, the penetrations ran largely parallel to the intraparietal sulcus, which allowed us to obtain a number of task-related neurons on each penetration because the electrode remained in LIP, and Fig. 4 shows a typical penetration. The MRI-based drawing (Fig. 4, left) shows the angle of the electrode with the gray area on the penetration through the middle third of the intraparietal sulcus and the location of neurons that were active during the delayed-saccade task. Nearly all neurons encountered (Fig. 4, middle) had visual responses, many were active during the instructed delay period, and some also increased their activity just before the saccade. In this penetration, FEF stimulation activated the majority of neurons and SC stimulation activated one neuron; none were activated by stimulation of both structures (Fig. 4, right).

The penetration in Fig. 4 illustrates the first conclusion on the organization of the projection neurons that we substantiate across our sample of LIP neurons: the output was to either FEF or SC, never both; the projection neurons were clearly segregated. In 26 penetrations in monkey $C$, in which at least one neuron was antidromically activated from either FEF or SC, eight had a combination of LIPfef and LIPsc neurons. In all eight penetrations, we encountered LIPfef neurons first, but in six penetrations, we again encountered LIPfef neurons below the LIPsc neurons. The limitation in monkey $C$, however, was that because the penetrations were nearly parallel to the sulcus, they did not cut sharply across the cortical layers, and it was therefore difficult to determine whether LIPfef neurons were located in layers distinct from the LIPsc neurons.

In the second monkey (monkey A), however, the issue of the relation of the projection neurons to cortical layering was easier to address because the penetrations were closer to being perpendicular to the intraparietal sulcus (Fig. 5, inset-also through the middle third of the sulcus). In 27 of 81 successful penetrations in this monkey, we encountered a combination of LIPfef and LIPsc neurons, and the plot in Fig. 5 shows the sequence of projection neurons for these 27 penetrations. In all of the penetrations we encountered LIPfef neurons before LIPsc neurons, and in 23 of these 27 penetrations (85\%), we found that the LIPfef neurons were followed only by LIPsc neurons with the distance between the deepest LIPfef neuron and the most superficial LIPsc being on average $913 \mu \mathrm{m}$. The penetrations in this monkey illustrate the second conclusion on the organization of the projection neurons: the LIPfef neurons lie more superficial in LIP than do the LIPsc neurons.

In addition to the antidromic activation from $\mathrm{FEF}$ and $\mathrm{SC}$, we also encountered 20 neurons in which there was an orthodromic response following FEF stimulation. The activation was recognized as orthodromic because it had long and variable latencies (2-12 ms), had more than a single action potential, and did not show colliding action potentials in the collision 


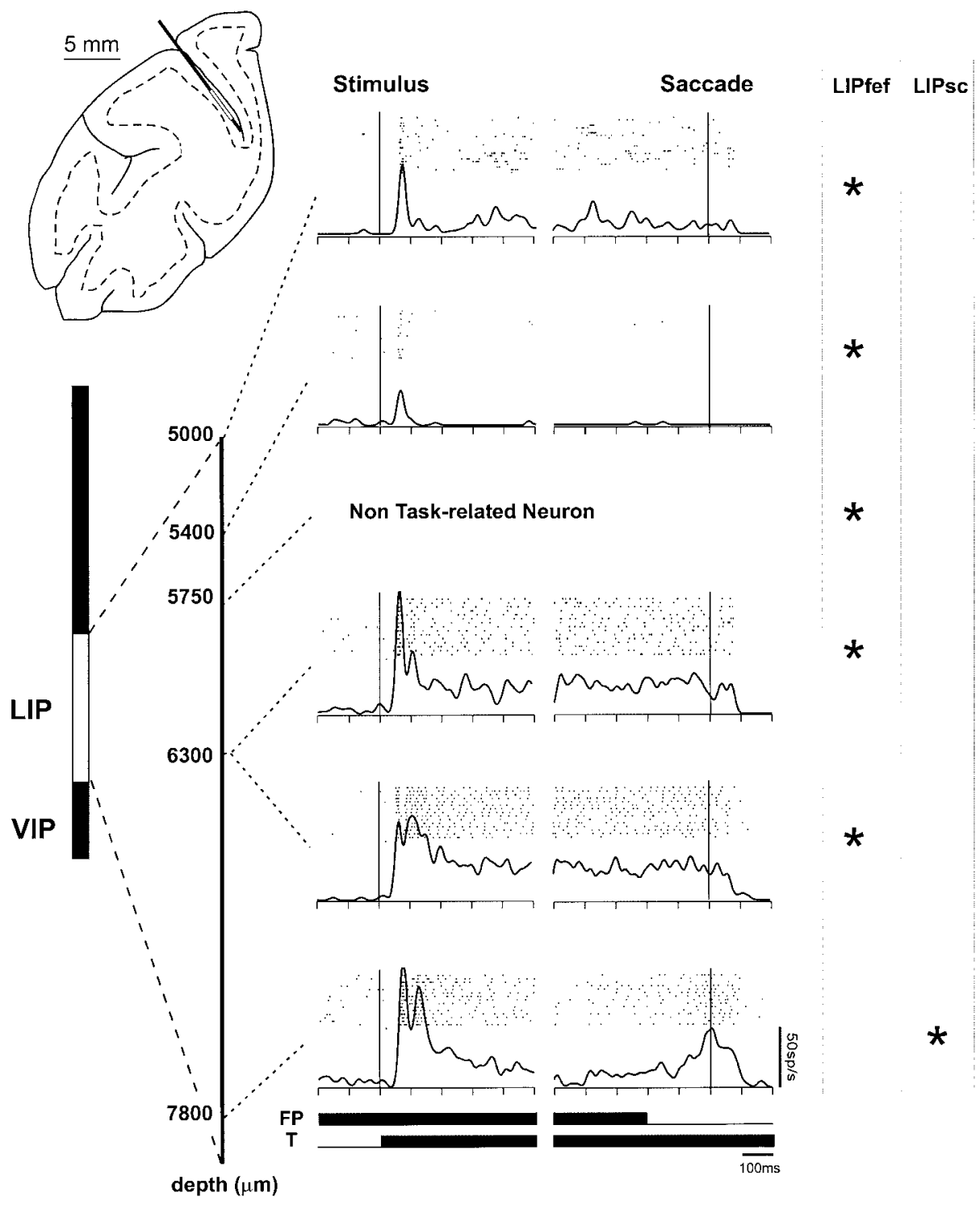

FIG. 4. Sample penetration through LIP showing the locations of neurons antidromically activated from FEF and SC in monkey C. Left: a drawing of a magnetic resonance imaging (MRI) section with the location of the electrode penetration indicated. This location was determined from an MRI taken with the electrode fixed in the grid at the same location as during the recording experiment. The gray region of the line indicates the region of the penetration in which visual and saccade neurons were encountered, and this line is expanded below to show the depth of the individual neurons recorded. Middle: the rasters and spike density histograms show activity for all the neurons antidromically activated in this region. Rasters and spike densities ( sigma $=8 \mathrm{~ms}$ ) show the activity aligned on the onset of the visual stimulus (left) and the saccade (right). Right: which neurons were activated from FEF and which from SC.

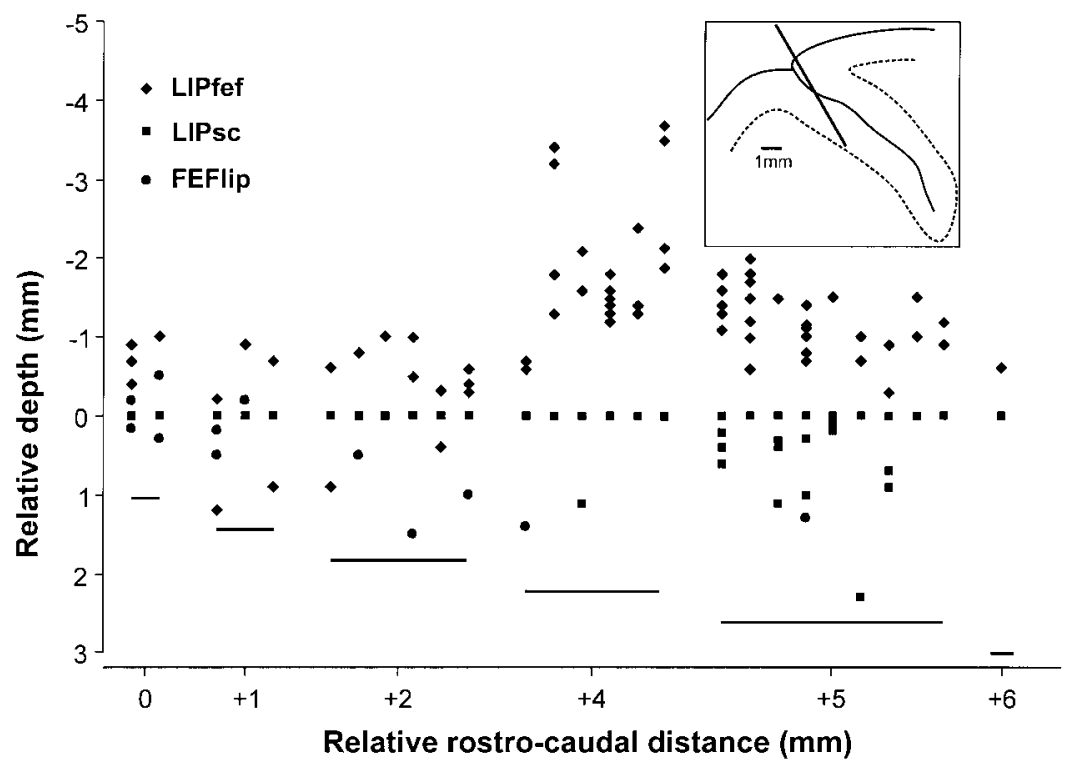

FIG. 5. Penetrations through LIP showing the distribution of LIPfef and LIPsc neurons in monkey A. The graph shows all penetrations in which both neurons activated from FEF and neurons activated from SC were encountered. Penetrations are ordered according to their rostrocaudal level with 0 indicating the most rostral penetration; bars under the penetrations indicate that those penetrations were recorded at the same rostralcaudal level. Depth values are aligned to the 1st neuron activated from SC found in each penetration. FEFlip indicates those LIP neurons orthodromically activated form the FEF. The drawing at the top (from the MRI) shows the typical angle of the penetrations in LIP in this monkey. The example shown is for the penetration at level +5 . The penetrations usually first traversed the medial bank of the sulcus, which was indicated by local limb-related activity. 
test. One of these 20 neurons was also activated orthodromically from SC and was the only orthodromically activated neuron from the SC found. These orthodromically activated neurons (FEFlip in Fig. 5) were deep in the penetration and were closer to the LIPsc neurons than to the LIPfef neurons. The mean current threshold for this orthodromic activation was $631 \pm 308 \mu \mathrm{A}$ (range 200-1,100). We were only able to study 11 of these neurons during the delayed-saccade task. All 11 were active in the task and had visual responses, delay activity, or saccade-related activity similar to the other LIP neurons.

In many tracks in both monkeys, when the electrode advanced beyond the LIPsc neurons, the neurons became distinctly visual and were presumably in the ventral intraparietal (VIP) area, which is located in the fundus of sulcus. The border between area LIP and VIP was usually physiologically well identified by the abrupt end of modulation of the background multiunit recording during the delayed-saccade task and the beginning of modulation by visual motion. This strong sensitivity to visual motion has been documented by Colby et al. (1993). We found that some of these VIP neurons could be antidromically activated by either FEF or SC stimulation (Paré et al. 1999).

The two major conclusions across our sample of LIP neurons are that the LIP output neurons projected to either FEF or $\mathrm{SC}$, never both, and that these projection neurons were clearly segregated with the LIPfef neurons lying more superficial than the LIPsc neurons.

\section{Comparison of LIPfef and LIPsc neurons in the delayed- saccade task}

We were able to adequately characterize 141 of the LIPfef neurons and 54 of the LIPsc neurons during the delayedsaccade task, all neurons whose antidromic activation was confirmed by the collision test.

We first found that more LIPsc neurons than LIPfef neurons changed their activity during the performance of the delayedsaccade task. While more than two-thirds of the LIPsc neurons $(37 / 54,69 \%)$ showed changes in activity in at least one phase of the task (visual, delay, or saccade period in either the visual or memory delayed-saccade task), less than half of the LIPfef neurons did $(62 / 141,44 \%)$, and this difference was statistically significant $\left(\chi^{2}=8.46\right.$, df $\left.=1, P<0.005\right)$. The neurons that did not change their activity were frequently at the same depth as neurons that did, and there were no differences in the threshold and latency of antidromic activation between them.

For those neurons that were modulated during the delayedsaccade task, we found both LIPfef and LIPsc neurons that changed their activity during all phases of the task. For example in Fig. 6, the two LIPfef neurons and one LIPsc neuron showed an increase in activity in response to the visual stimulus and sustained activity during the delay period although there was substantial variation between neurons and between the visual and memory trials. There was only a modest increase in activity just before the saccades for two of the three illustrated neurons. Figure $7 A$ shows the frequency of activity in the visual, delay, and saccadic periods across our sample of LIPfef and LIPsc neurons that were tested in both the visual and the memory versions of the delayed-saccade task (60 LIPfef and 31 LIPsc neurons).

There were, however, two interesting differences between the LIPfef and LIPsc neurons that were active in the delayedsaccade task. First, while the proportion of neurons with visual or delay activity was similar in the LIPfef and LIPsc neurons (Fig. 7A), LIPfef neurons had saccade-related activity significantly less often than did LIPsc neurons (Fig. 7A, SAC; 10/60, $17 \%$ vs. $13 / 31,42 \%$; $\left.\chi^{2}, P<0.05\right)$. Second, a significantly higher proportion of LIPfef than LIPsc neurons had visual responses with no accompanying saccadic activity (Fig. $7 B$, VIS; $78 \%$ vs. $\left.55 \% ; \chi^{2}, P<0.05\right)$ and a significantly lower proportion of LIPfef than LIPsc neurons had saccade-related activity accompanying their visual response (Fig. 7B, VIS-SAC; $42 \%$ versus $\left.15 \% ; \chi^{2}, P<0.05\right)$.

The scatter plots in Fig. 8 show the magnitude of the visual response against the delay activity (Fig. $8, A$ and $B$ ) and the presaccadic activity against the delay activity (Fig. 8, $C$ and $D$ ). The salient point is the remarkable overlap in the visual, delay, and saccadic activity of the FEF and SC projection neurons in both the visual and memory delayed-saccade tasks. For both the FEF and SC projection neurons, the delay activity was less than the visual response as indicated by the large proportion of data points falling above the equality line (note the difference in axis labels), but the subsequent saccadic activity was only slightly greater than the delay activity.

To examine in more detail the signals possibly related to early saccade processing, we will consider only those neurons
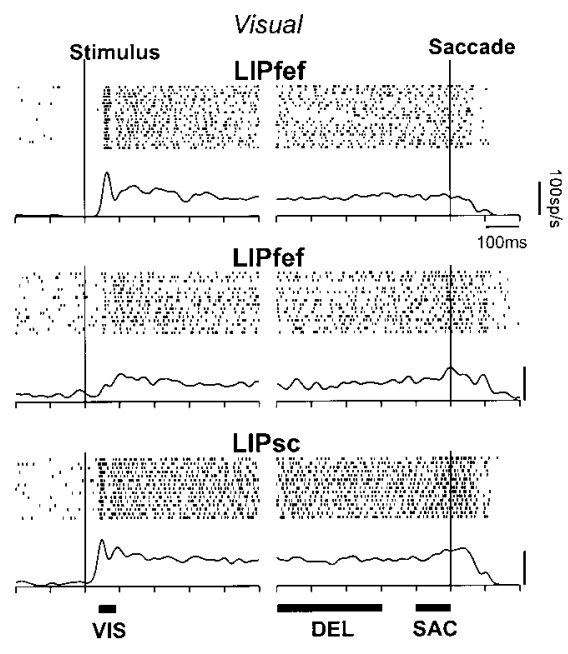
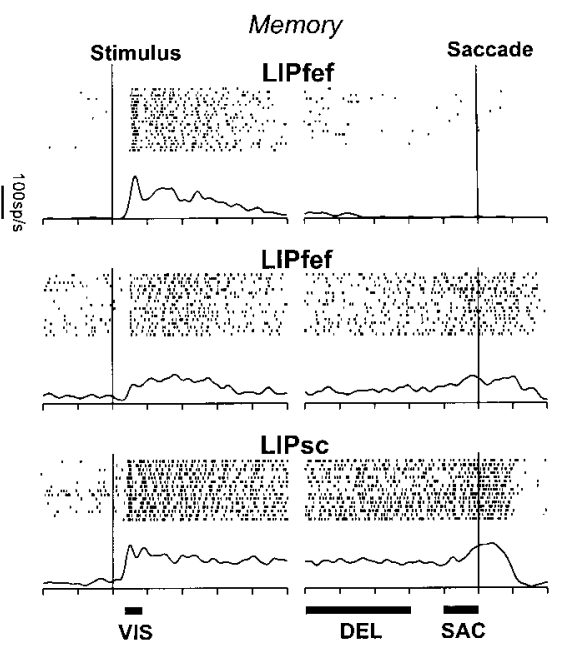

FIG. 6. Examples of 2 LIPfef neurons and 1 LIPsc neuron illustrating the range of activity patterns observed in LIP output neurons in the delayed-saccade task. The visual stimulus either remained on from its onset to the end of the trial (visual trials, left) or was only briefly presented (memory trials, right). Rasters and spike densities (sigma $=8 \mathrm{~ms}$ ) show the activity aligned on the onset of the visual stimulus (left) or the saccade (right). These data were collected with the visual stimulus presented near the center of the visual and movement fields. The LIPsc neuron also was orthodromically activated by FEF stimulation. 

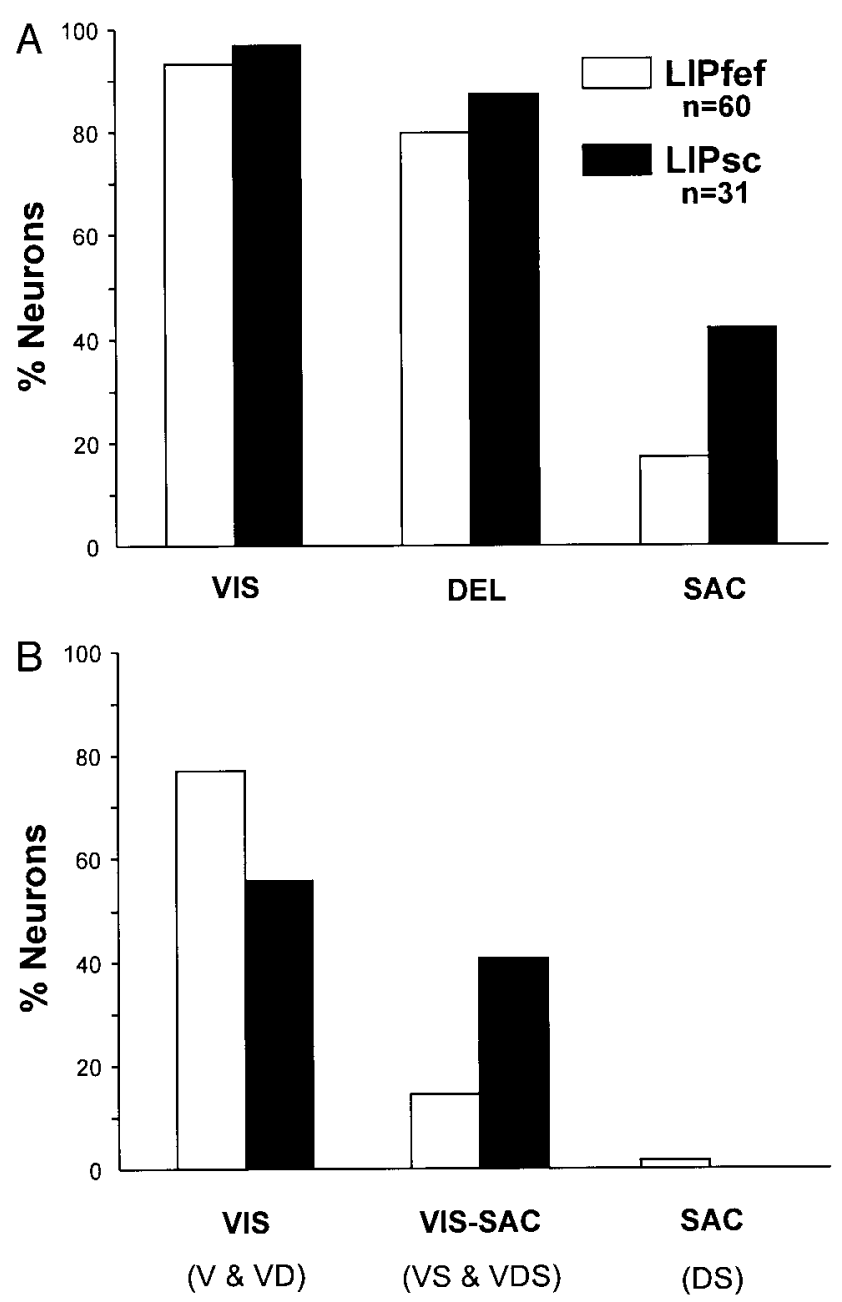

FIG. 7. Activity of LIPfef and LIPsc neurons that had significant changes in activity during the delayed-saccade tasks. $A$ : bar graph showing the percent of neurons that were significantly modulated during the successive phases of the task. VIS, stimulus activity significantly greater than fixation activity; DEL, delay activity significantly greater than fixation activity; SAC, saccade activity significantly greater than delay activity. The visual activity was the mean discharge rate during a 50-ms interval starting at the onset of the stimulusrelated response (or from 50 to $100 \mathrm{~ms}$ if there was no significant response), the delay activity was the mean rate during the last $300 \mathrm{~ms}$ of the delay period, and the saccadic activity was the mean rate during a 100 -ms interval ending at saccade onset. Neurons were included if the activity difference in any phase of the activity was statistically significant (Wilcoxon signed-rank test, $P<0.01$ ) in either the visual or the memory-guided delay task (LIPfef, $n=60$; LIPsc, $n=31$ ). For the LIPfef and LIPsc neurons, respectively, the values were: visual responses, 56/60, 93\% and 30/31, 97\%; delay activity, 48/60, 80\% and $27 / 31,87 \%$; saccadic activity, 10/60, 17\% versus $13 / 31,42 \%$. For each neuron, each activity type could be present in all the possible combinations. $B$ : bar graph showing the percent of neurons that have visual responses (VIS), saccade-related activity (SAC), and both visual and saccade activity (VIS-SAC). All responses are defined as in $A$ and are for the same set of neurons shown in $A$. For brevity, the combinations in each larger group use the abbreviations V, D, and S for visual, delay, and saccade activity. Note the paucity of neurons with saccade only activity.

(48 LIPfef and 27 LIPsc) that had delay activity significantly greater than their fixation activity in either visual or memory trials (Wilcoxon signed-rank test, $P<0.01$ ). A Kruskal-Wallis ANOVA on ranks showed that there was a statistically significant difference among the groups $(P<0.0001$; visual, delay and saccadic activity in visual and memory trials for both LIPfef and LIPsc). An all pair-wise multiple comparisons
(Tukey HSD method, $P<0.05$ ) between the LIPfef and LIPsc neurons revealed significant differences in the delay activity during visually guided saccade trials and in the saccadic activity during both visual and memory-guided saccade trials (no significant differences were found for the delay activity in the memory trials or for any visual response). The saccadic activity also differed significantly from the preceding delay activity in all cases except for the LIPfef neurons in memory trials. For both the LIPfef and LIPsc neurons, there was significantly greater delay and saccadic activity during the visual than during the memory-guided saccade trials.

To quantify the magnitude of the difference in the delay and saccadic activity in the visual and memory trials, we used an ordinal dominance analysis (Darlington 1973), which we applied previously to the LIPsc neurons (Paré and Wurtz 2001) and is similar to the well-established receiver operating characteristic (ROC) analysis (Bamber 1975; Green and Swets 1966). Briefly, we compared the frequency of individual trials on which the neuron had a given discharge rate on the visual and memory trials and from this derived a visual/memory separation index (see Paré and Wurtz 2001). This index gives the probability that given one draw from each distribution of activity rates, the rate from the activity distribution in visual trials would be larger. A chance probability value of 0.5 thus implies completely overlapping distributions. A value $>0.5$ indicates that the activity distribution in visual trials is separate from and greater than the memory distribution, and a value $<0.5$, the converse. Figure 9 shows that the distributions for both the LIPfef and LIPsc neurons had median values that were significantly $>0.5$ (Mann-Whitney rank sum test, $P<0.0001$ ); this confirms that the activity in visual trials was greater than in memory trials. When the index distributions of LIPfef and LIPsc neurons were compared, none of them was statistically different (Kruskal-Wallis ANOVA on ranks, $P=0.02$; Dunn's test, $P>0.05)$. Thus despite differences in their level of delay and presaccadic activity, LIPfef and LIPsc neurons possessed a similar dependence on the sustained presence of the visual stimulus.

In summary, we found a striking similarity between the LIPfef and LIPsc neurons: they both had visual, delay, and saccadic activity. Both output neuron types also had more vigorous delay and saccadic activity in the visual than in the memory tasks. A major difference between the two projection neuron types was that fewer LIPfef than LIPsc neurons were active in the delayed-saccade task at all. Among those that were active, more LIPfef than LIPsc neurons had visual responses not accompanied by any saccade-related activity and more LIPsc than LIPfef neurons had saccadic activity. LIPsc neurons also had a higher level of both delay and saccadic activity than did LIPfef neurons.

\section{Comparison of disparity sensitivity}

We tested 57 LIPfef neurons and 30 LIPsc neurons for disparity sensitivity; 28 of the 57 LIPfef neurons and 19 of the 30 LIPsc neurons were active in the delayed-saccade task; the rest were not active. Figure 10 illustrates the responses of a disparity sensitive neuron to a spot of light in the center of its receptive field. Near stimuli evoked stronger neuronal responses than did far stimuli. The responses frequently had two 

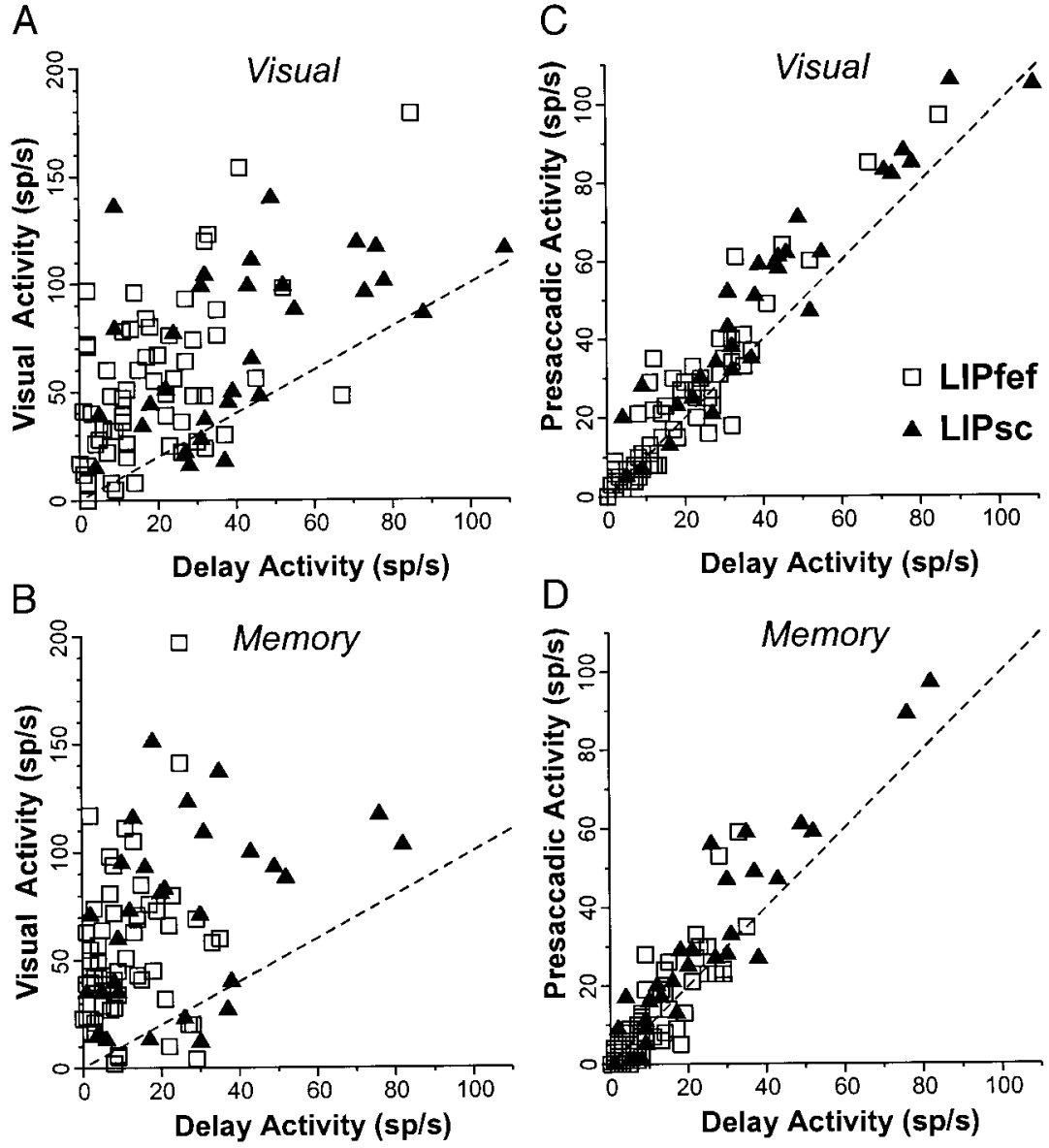

FIG. 8. Discharge properties of LIPfef neurons ( $\square, n=$ $60)$ and LIPsc neurons $(\Delta, n=31)$ recorded in area LIP during the visual (top) and the memory (bottom) trials of the delayed-saccade task. $A$ and $B$ : scatter plots of the magnitude of the stimulus activity against the magnitude of the delay activity. $C$ and $D$ : scatter plots of the magnitude of the saccadic activity against the magnitude of the delay activity. Each data point indicates the mean value of each parameter for each neuron taken in the same time periods as in Fig. $7 \mathrm{~A}$. phases that could be divided into an early (50 to $200 \mathrm{~ms}$ after stimulus onset) and a late phase (300-1,000 ms), and we therefore quantified the disparity sensitivity of the LIP neuronal samples using these early and late analysis epochs. Of the LIPfef neurons, 26/57 (46\%) were significantly modulated by disparity stimuli $(89 \%, 25 / 28$ of those that were active in the delayed-saccade task) as were $15 / 30(50 \%)$ of the LIPsc neurons $(74 \%, 14 / 19$ active in the saccade task) in at least one of the two analysis epochs (Kruskal-Wallis ANOVA on ranks, $P<0.05)$.

Figure 11 illustrates the variation seen in the disparity tuning by showing the tuning curves for two LIPfef ( $A$ and $B$ ) and two LIPsc ( $C$ and $D$ ) neurons. The salient point is that the neurons are broadly tuned over the near and far disparities that we tested rather than responding over only a narrow range of disparities. Most neurons (69\%, 18/26 of LIPfef neurons and $87 \%, 13 / 15$ of LIPsc neurons) responded to disparities that were near or far (Fig. 11, $A-C$ ) (Poggio and Fischer 1977). In both the LIPfef and LIPsc neurons, there was a prevalence of far neurons: (67\%, 12/18 of LIPfef neurons and 69\%, 9/13 of LIPsc neurons) - values similar to the far prevalence among FEF neurons (Ferraina et al. 2000). The remainder had peak responses near zero (Fig. 11D, 10 of the projection neurons). The modulation of the early or late responses was sometimes quite similar (Fig. 11, $A$ and $D$ ) but also differed in many cases (Fig. 11, $B$ and $C$ ).

To test the hypothesis that the disparity sensitivity observed in our samples might be constructed from the linear combination of two monocular response fields, we examined further the responses of 10 LIP output neurons $(8$ LIPfef and 2 LIPsc
Delay Activity

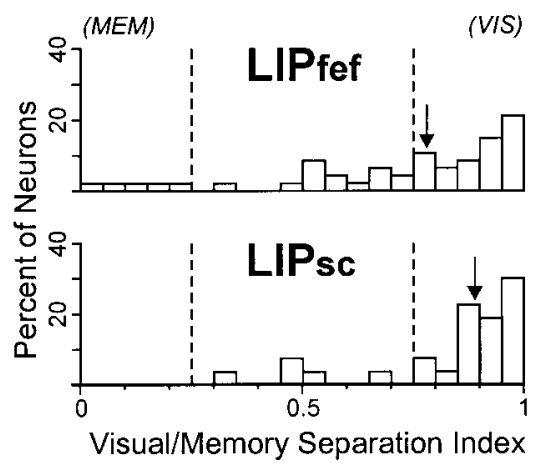

Presaccadic Activity
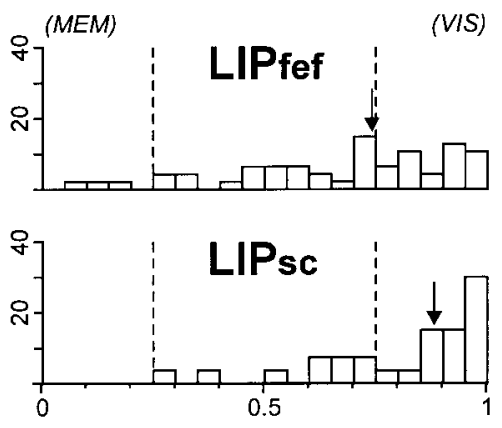

Visual/Memory Separation Index
FIG. 9. Distribution of the visual/memory separation index for the LIPfef neurons ( $n=48)$, and LIPsc neurons $(n=$ 27 ) during the delay and presaccadic epochs of the delayedsaccade task. This analysis is based on the distribution of the discharge rates in each analysis epoch. The index can take a value from 0 (memory distribution completely separate from and greater than visual distribution) to 1 (visual distribution completely separate from and greater than memory distribution). A value of 0.5 indicates that visual and memory distributions are indistinguishable. -- -, the thresholds of statistical significance. $\downarrow$, the median index value of each distribution for the delay and presaccadic distributions, respectively: 0.78 and 0.74 for the LIPfef neurons; 0.89 and 0.88 for the LIPsc neurons. Bin width is 0.05 . 


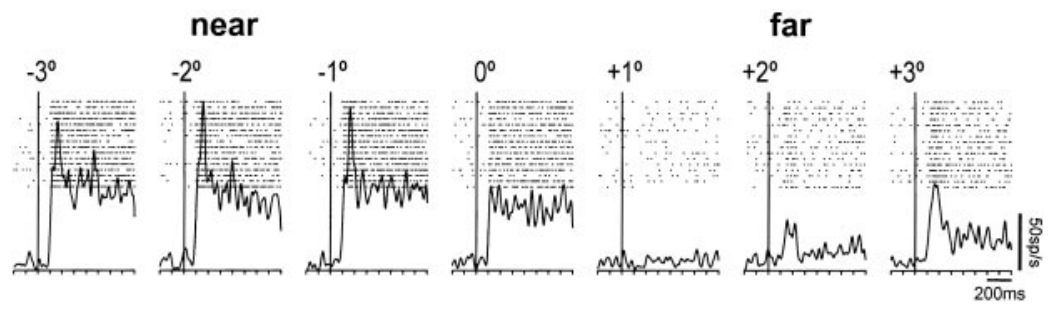

FIG. 10. Example of an LIPfef neuron that was sensitive to stimulus disparity. Rasters and spike densities show the activity aligned on the onset of the visual stimulus presented with a disparity ranging from $-3^{\circ}$ (near) to $+3^{\circ}$ (far). Rasters and spike densities (sigma $=8 \mathrm{~ms}$ ) are aligned on stimulus onset.

neurons). We compared each neuron's responses to binocular disparity stimuli with those elicited by monocular stimuli presented at similar retinal positions. The monocular viewing was done either by patching one and then the other eye or by presenting only one of the two halves of the visual stimulus. In none of the neurons could the response to the binocular response be accounted for by a simple linear combination of the two monocular responses, and Fig. 12 shows typical results for one LIPfef $(A)$ and one LIPsc $(B)$ neuron. Significant changes in the mean discharge rate of these two neurons were observed when the stimuli were presented binocularly $(\diamond)$ but not during monocular presentations to either eyes ( $\triangle$ and $\square$ ).

To further compare the early and late responses, we performed a partial correlation analysis. This analysis verifies, for each neuron, the correlation of the observed values for the early and late responses while controlling for the different disparity values. Early and late responses correlated in $85 \%$ of the projection neurons (35/41) including both the LIPfef $(21 / 26 ; 80.8 \%)$ and LIPsc neurons $(14 / 15 ; 93.3 \%)$. In contrast, a sample of FEF neurons recorded in the FEF of the same monkey (Ferraina et al. 2000), only 50\% (18/36) had early and late responses that significantly correlate $(P<0.05)$. In summary, many of the LIP neurons projecting to either FEF or SC were broadly tuned for disparity, and there was a tendency to prefer far stimuli.

\section{I S C U S S I O N}

\section{Segregation of LIP output but overlap of function}

The investigation of the outputs from LIP offers an exceptional opportunity to begin to study a circuit in the primate brain underlying a simple behavior. First, we can identify multiple outputs of LIP because we know the target areas of the axons from previous anatomical studies, we can identify several of these target areas by the character of their neuronal activity, and we can therefore position stimulation electrodes to antidromically identify the LIP output neurons. Second, one of the LIP outputs that can be so identified is to a cortical area, the other to a subcortical area so that the activity in the corticocortical outputs can be compared with that exiting the cortex. Third, because much is known about the activity in the target areas, the activity of the output neurons of LIP can be compared with those in the target structures, which in turn allows inferences about the sequential processing between areas. Thus our observations on the LIP output neurons should have implications not only for understanding the saccadic system but also for understanding the progression of signal processing in the brain, at least in relatively simple circuits.

Our first finding was that the output neurons to cortex (LIPfef) and to brain stem (LIPsc) were segregated; we never encountered a neuron antidromically activated from both FEF
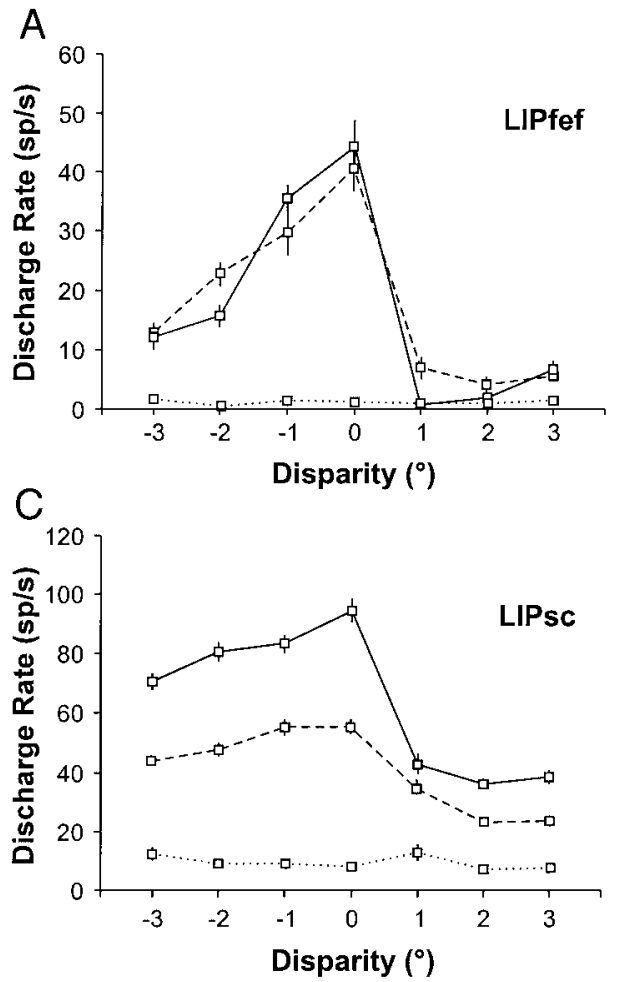
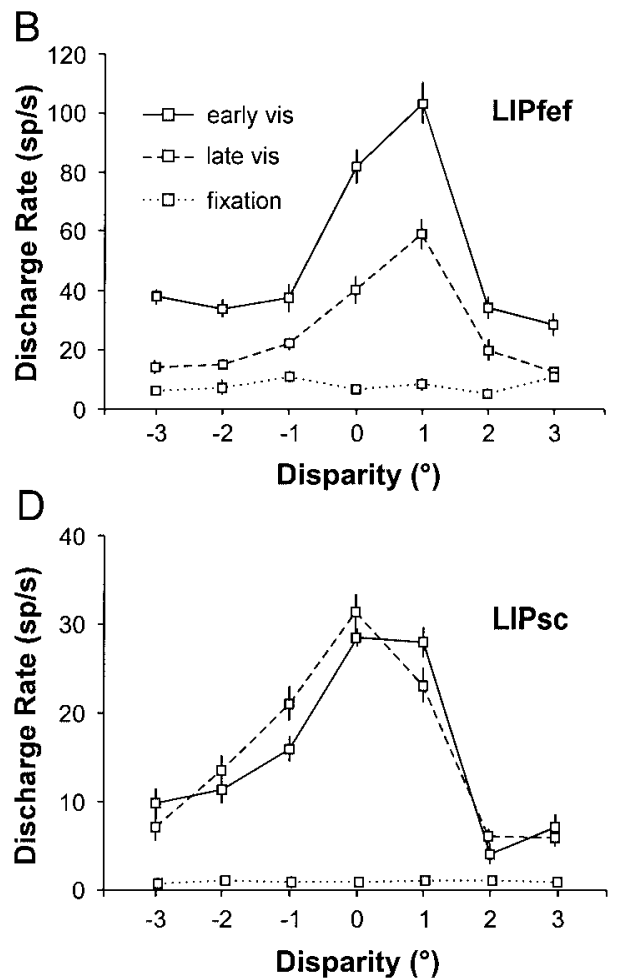

FIG. 11. Disparity tuning of LIP output neurons. Examples from 2 LIPfef $(A$ and $B)$ and 2 LIPsc $(C$ and $D)$ neurons. Mean $\pm \mathrm{SE}$ discharge rate are shown for each disparity value tested. 

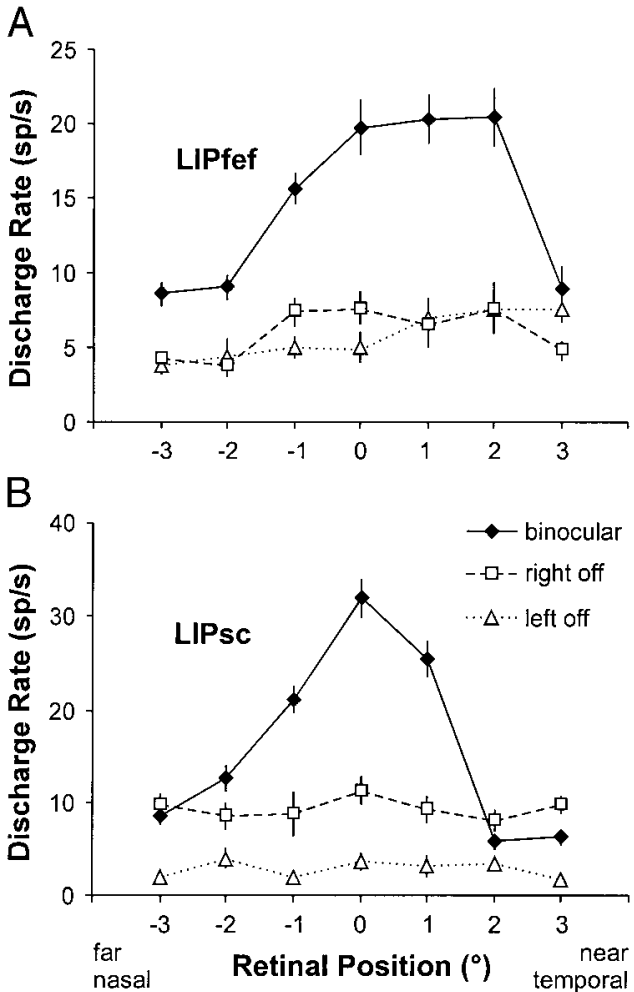

FIG. 12. Comparison of the responses of LIP neurons to visual stimuli presented at identical retinal positions during binocular and monocular conditions. Mean $\pm \mathrm{SE}$ discharge rate are shown for each disparity value tested.

and SC. While we may well have missed LIP neurons that projected to both FEF and SC, this would not alter our observation that many LIP neurons are organized into two completely separate output channels. This segregation of LIP cortical and subcortical output neurons is similar to that found for neurons in motor cortex (Bauswein et al. 1989; Turner and DeLong 2000). In our study, neurons projecting to FEF were also found higher in the cortical layers than were those projecting to SC. This is consistent with the anatomically established observation that LIPfef neurons are frequently located in layer III and that LIPsc neurons are exclusively in layer V (Andersen et al. 1985; Barbas and Mesulam 1981; Fries 1984; Huerta et al. 1987; Lynch et al. 1985; Schall et al. 1995). Our results, however, do not reject the possibility that LIPfef neurons are also present in the infragranular layers as a number of the anatomical studies clearly show (Huerta et al. 1987; Schall et al. 1995; Tian and Lynch 1996). We also estimated that the conduction velocities for the LIPfef neurons were lower than those for the LIPsc neurons indicating that the corticocortical axons are generally smaller than the subcortical axons. This is in agreement with previous physiological studies of corticocortical neurons (Swadlow et al. 1978).

On the basis of this separation of neurons, and possibly of the layers of origin, one might predict that these two projections would convey different information: the LIPsc neurons might convey information closely related to the impending saccade; the LIPfef might convey higher level information. Our results do not support such an idea of substantial separation because we find that the LIPfef and the LIPsc both have responses to visual stimulation, continuing activity in the delay period, and increased activity before the saccade, with the proviso that the LIPfef neurons were less frequently active in the behavioral tasks that we used. We therefore conclude that there is clear segregation in the output neurons directed to cortex and brain stem, but no strong evidence for segregation in the signals that they carry.

\section{Activity of LIP output neurons during the saccade task}

While the information conveyed from LIP to FEF and SC may not be qualitatively different, we found clear evidence that the information conveyed is quantitatively different. A substantial difference was the larger proportion of LIPfef than LIPsc neurons having visual activity with no associated saccade related activity, and the larger proportion of LIPsc than LIPfef neurons that had any saccade related activity. This greater dependence on the visual stimulus in the LIPfef neurons was also evident in their relatively higher delay activity in the visual than in the memory-guided saccade task. Furthermore, this difference between the visual and memory trials of the LIPfef and LIPsc neurons is based on the magnitude of the activity in the neurons studied rather on just the frequency with which the neuronal types were encountered and is therefore less dependent on any possible biases in neuron sampling. Other limitations of the antidromic technique as we have used it have been discussed previously (Paré and Wurtz 2001; Sommer and Wurtz 2000).

These two observations taken together suggest that the signals conveyed from LIP to FEF are heavily visual. This would be consistent with the anatomical analysis of Bullier et al. (1996), who placed LIP on one of the major pathways between occipital and frontal cortex. This implies that the visual activity in FEF would be more likely to be dependent on input from LIP than would the saccade-related activity in FEF. What we do not know at this point is the fraction of the visual activity in FEF that is dependent on this flow through LIP.

Possibly the major difference between the cortical and subcortical output was the higher frequency of LIPfef neurons that were not active in the delayed-saccade task. We do not know whether these neurons convey visual or oculomotor information that are not required in our task or whether they are related to other behaviors. One possibility is that these neurons were task-related in our study but rapidly adapting because of the low cognitive demands of the behavioral tasks we used.

The LIPsc neurons more frequently have increased activity before saccades than do the LIPfef neurons; but in previous studies (Paré and Wurtz 1997, 2001), the LIPsc neurons were found to have less saccade-related activity than the SC neurons themselves. Thus we find essentially an increasing movement predominance as we go from the LIPfef neurons to the LIPsc neurons to the SC neurons themselves.

\section{Disparity sensitivity of LIP output neurons}

We included a survey of disparity sensitivity of the LIP projection neurons after we began finding many neurons that were not active in the delayed-saccade task and after we noticed the tendency for some neuronal responses to vary with the distance of the stimuli from the monkey. Only a few neurons that were disparity sensitive turned out to be unresponsive in the delayed-saccade task. The disparity sensitivity that we observed was remarkably similar to that reported for 
neurons in the LIP region by Gnadt and Mays (1995): the disparity-sensitive neurons were frequently those that were also active in the visual-motor sequence leading to a saccade, they had broad tuning curves with a variety of shapes, and they had distinguishable early and late responses. That the disparitysensitive neurons that we identified also projected to the SC confirmed the earlier report that many of these LIP neurons convey this depth information to the SC (Gnadt and Beyer 1998), and our antidromic latencies were in the same range as those of the previous study $[2.0 \pm 0.8$ and $1.3 \pm 0.67$ (SD), respectively]. What we can now appreciate for the first time is that these disparity signals are conveyed to the FEF as well as to the SC. We did not identify substantial differences in the disparity responses of the LIPfef and LIPsc neurons.

The disparity signals in FEF neurons (Ferraina et al. 2000, which were recorded in the same 2 monkeys as in the present study) also show substantial similarities to the LIP output neurons of the present study. All of the FEF neurons, like most of the LIP output neurons, were active in the delayed-saccade task, and neurons in both areas had broadly tuned disparity functions with a variety of disparity preferences. They also both had a tendency to prefer far as opposed to near disparity. The similarity between the LIP output neurons and disparitysensitive neurons in the FEF is consistent with the hypothesis that LIP is a major contributor of disparity information in FEF.

Disparity signals are essential not only for stereoscopic perception of depth but also for vergence eye movements. The combination of such broadly tuned disparity signals and the presence of neurons with saccadic activity raise the possibility that such neurons could have a role in the production of disconjugate saccades, those saccades made from one plane in depth to another that require both version and vergence eye movements. Behavioral studies have shown that the vergence and saccadic systems actively cooperate during disconjugate saccades (Chaturvedi and van Gisbergen 1998; Erkelens et al. 1989; Maxwell and King 1992; Zee et al. 1992). Moreover, because the same type of disparity signals have been found in both LIP and FEF, both areas could play a role in the production of disjunctive saccades. The test of such involvement in both areas will require recording during saccades to targets in three-dimensional space where the vergence and the version component of the saccade can be easily dissociated. Also, it has recently been shown that neurons in the frontal cortex just rostral to the FEF change their activity specifically in relation to vergence eye movements rather than to the disparity signals contributing to the vergence change (Gamlin and Yoon 2000). The disparity input for such vergence changes might be relayed via the projection from LIP to FEF or directly from LIP to this adjacent cortex.

\section{LIP as a node in a distributed system for saccade generation}

The combination of the overlap in the output signals from LIP to FEF and to SC and the indication of quantitative differences between many of the signals in the two pathways suggest that LIP might best be regarded as part of a distributed system for the generation of saccadic eye movements. Because the same overlap of processing with a quantitative shift is seen in the outputs of LIP (Paré and Wurtz 1997, 2001) and FEF (Sommer and Wurtz 2000, 2001) to the SC, these other areas might equally well be regarded as part of the same distributed system (reviewed in Wurtz et al. 2001). This concept was proposed by Lynch and colleagues (Lynch et al. 1977) and subsequently supported by anatomical and physiological experiments on the distributed nature of the saccadic and pursuit systems (Lynch 1992; Tian and Lynch 1996). Similar conclusions on distributed systems have been reached in several other investigations of the interaction between parietal and frontal areas and the model has been then extended to other motor systems (Alexander and Crutcher 1990; Caminiti et al. 1996; Crutcher and Alexander 1990; Johnson et al. 1996). Caminiti and colleagues (Caminiti et al. 1996; Johnson et al. 1996), for example, have shown that subregions of the parietal and frontal lobes, which share reciprocal anatomical connections, contain neurons with similar activities during visual reaching tasks, and Burnod and colleagues (1999) developed a model that incorporates the parallel architecture into a parieto-frontal network. A similar implied distribution of activity has been observed during a reaching task using working memory (Batuev et al. 1985; Quintana and Fuster 1992). The concurrent metabolic activation of the prefrontal and parietal cortex in monkeys performing working memory tasks (Friedman and Goldman-Rakic 1994), as well as the similarities of neuronal activity and the similarity of effects of inactivation of prefrontal area $8 \mathrm{a}$ and parietal area 7 ip during a working memory saccade task (Chafee and Goldman-Rakic 1998, 2000) led Goldman-Rakic and colleagues to conclude that information is shared across interacting cortical areas. Additional evidence for such a distributed cortical organization of the oculomotor system also comes from imaging studies in humans during a working memory saccade task (Jonides et al. 1993; Sweeney et al. 1996) or a saccade/pursuit task (Petit and Haxby 1999).

This notion of a distributed system, however, implies that the processing is distributed not that all the areas are equally involved in all phases of saccade generation or that signals flow haphazardly within the system. The benefit of studying neurons whose destination within the brain has been determined is the ability to distinguish the more subtle differences between the signals passing between the areas even in the presence of great overlap of the signals across the areas. In the generation of saccades, on which our laboratory has concentrated in this and a related series of experiments (Paré and Wurtz 1997, 2001; Sommer and Wurtz 2000, 2001), the outputs we know something about are those from LIP to SC, from FEF to SC, and from LIP to FEF. From the present study we know that the outputs from LIP frequently convey visual and delay period information with less saccadic activity going to FEF than to SC. In contrast, FEF output neurons have much more saccaderelated activity than do the LIP output neurons although the FEF neurons have visual and delay activity as well. A logical interpretation of this configuration of properties is that there is a progression of visual activity from LIP to FEF for determining target location and that this information may be given in three-dimensional coordinates. Similar visual information would be provided by LIP to SC. The role of LIP would therefore be largely to convey visual and delay information to FEF and SC. Saccade-related activity in FEF (including the FEF outputs) and in SC would then be dependent on this input either directly or indirectly. As an aside, this raises the possibility that the relatively modest saccade-related activity within LIP is a result of the projection to LIP from FEF, but because the signals conveyed from FEF to LIP are not known, this is 
only speculation. Our overall conclusion is that while we have found extensive overlap between the areas, there is clear indication of a gradual progression of the signals from one area to another when the nature of the outputs is recognized.

We thank the Laboratory of Diagnostic Radiology Research for magnetic resonance images and T. Ruffner, A. Nichols, and M. Smith for assistance during the experiments.

S. Ferraina was supported by a Human Frontiers Science Program fellowship.

Present addresses: S. Ferraina, Dipartimento di Fisiologia Umana e Farmacologia, Università "La Sapienza," 00185 Rome, Italy; M. Paré, Dept. of Physiology and CIHR Group in Sensory-motor Systems, Queen's University, Kingston, Ontario K7L 3N6, Canada.

\section{REFERENCES}

Alexander GE AND CRUTCher MD. Preparation for movement: neural representations of intended direction in three motor areas of the monkey. J Neurophysiol 64: 133-150, 1990.

Andersen RA, Asanuma C, and Cowan M. Callosal and prefrontal associational projecting cell populations in area $7 \mathrm{a}$ of the macaque monkey: a study using retrogradely transported fluorescent dyes. J Comp Neurol 232: 443$455,1985$.

Andersen RA, Asanuma C, Essick G, and Siegel RM. Corticocortical connections of anatomically and physiologically defined subdivisions within the inferior parietal lobule. J Comp Neurol 296: 65-113, 1990.

ANDERSEn RA, SNyder LH, BRAdLEy DC, AND Xing J. Multimodal representation of space in the posterior parietal cortex and its use in planning movements. Аппи Rev Neurosci 20: 303-330, 1997.

BAMBER D. The area above the ordinal dominance graph and the area below the receiver operating characteristic graph. J Math Psychol 12: 387-415, 1975.

BARBAS H AND MESUlam M-M. Organization of afferent input to subdivisions of area 8 in the rhesus monkey. J Comp Neurol 200: 407-431, 1981.

BATUEV AS, SHAEFER VI, AND ORLov AA. Comparative characteristics of unit activity in the prefrontal and parietal areas during delayed performance in monkeys. Behav Brain Res 16: 57-70, 1985.

Bauswein E, Fromm C, and Preuss A. Corticostriatal cells in comparison with pyramidal tract neurons: contrasting properties in the behaving monkey. Brain Res 493: 198-203, 1989.

Blatt GJ, ANDERSEN RA, AND STONER GR. Visual receptive field organization and cortico-cortical connections of the lateral intraparietal area (area LIP) in the macaque. J Comp Neurol 299: 421-445, 1990.

Bruce CJ, Goldberg ME, Stanton GB, and Bushnell MC. Primate frontal eye fields. II. Physiological and anatomical correlates of electrically evoked eye movements. J Neurophysiol 54: 714-734, 1985.

Bullier J, Schall JD, AND Morel A. Functional streams in occipito-frontal connections in the monkey. Behav Brain Res 76: 89-97, 1996.

Burnod Y, Baraduc P, Battaglia-Mayer A, Guigon E, Koechlin E, Ferraina S, Lacquaniti F, and Caminiti R. Parieto-frontal coding of reaching: an integrated framework. Exp Brain Res 129: 325-346, 1999.

CAminiti R, FERRAINA S, AND Johnson PB. The sources of visual information to the primate frontal lobe: a novel role for the superior parietal lobule. Cereb Cortex 6: 319-328, 1996.

Chafee MV AND GoldMAN-RAKIC PS. Matching patterns of activity in primate prefrontal area 8a and parietal area 7ip neurons during a spatial working memory task. J Neurophysiol 79: 2919-2940, 1998.

Chafee MV AND Goldman-RAKIC PS. Inactivation of parietal and prefrontal cortex reveals interdependence of neural activity during memory-guided saccades. J Neurophysiol 83: 1550-1566, 2000.

Chaturvedi V AND VAn Gisbergen JA. Shared target selection for combined version-vergence eye movements. J Neurophysiol 80: 849-862, 1998.

Colby CL, Duhamel J-R, AND GoldBerg ME. Ventral intraparietal area of the macaque: anatomic location and visual response properties. J Neurophysiol 69: 902-914, 1993.

Colby CL and Goldberg ME. Space and attention in parietal cortex. Annu Rev Neurosci 23: 319-349, 1999.

CRIST CF, YAmasaki DSG, Komatsu H, AND WuRTZ RH. A grid system and a microsyringe for single cell recording. J Neurosci Methods 26: 117-122, 1988.

CRUTCher MD AND AlEXANDER GE. Movement-related neuronal activity selectively coding either direction or muscle pattern in three motor areas of the monkey. J Neurophysiol 64: 151-163, 1990.
DARLINGTON RB. Comparing two groups by simple graphs. Psychol Bull 79: 110-116, 1973.

Dias EC AND Segraves MA. Muscimol-induced inactivation of monkey frontal eye field: effects on visually and memory-guided saccades. $J \mathrm{Neu}$ rophysiol 81: 2191-2214, 1999.

EIFUKU S AND WURTZ RH. Response to motion in extrastriate area MSTl: disparity sensitivity. J Neurophysiol 82: 2462-2475, 1999.

ERkelens CJ, van der Steen J, Steinman RM, and Collewijn H. Ocular vergence under natural conditions. I. Continuous changes of target distance along the medial plane. Proc R Soc Lond B Biol Sci 236: 417-440, 1989.

Ferraina S, PARÉ M, AND WURTZ RH. Discharge properties of lateral intraparietal neurons antidromically activated by frontal eye field stimulation. Soc Neurosci Abstr 25: 806, 1999.

FERRAINA S, PARÉ M, AND WURTZ RH. Disparity sensitivity of frontal eye field neurons. J Neurophysiol 83: 625-629, 2000.

FRIEDMAN HR AND GOLDMAN-RAKIC PS. Coactivation of prefrontal cortex and inferior parietal cortex in working memory tasks revealed by $2 \mathrm{DG}$ functional mapping in the rhesus monkey. J Neurosci 13: 2775-2788, 1994.

FRIES W. Cortical projections to the superior colliculus in the macaque monkey: a retrograde study using horseradish peroxidase. J Comp Neurol 230: 55-76, 1984.

GAMLIN PD AND YoOn K. An area for vergence eye movement in primate frontal cortex. Nature 407: 1003-1007, 2000.

GNADT JW AND BEYER J. Eye movements in depth: what does the monkey's parietal cortex tell the superior colliculus? Neuroreport 9: 233-238, 1998.

GNADT JW AND MAYs LE. Neurons in monkey parietal area LIP are tuned for eye-movement parameters in three-dimensional space. J Neurophysiol 73: 280-297, 1995.

GReEn DM AND Swets JA. Signal Detection Theory and Psychophysics. New York: Wiley, 1966.

Horwitz GD And Newsome WT. Separate signals for target selection and movement specification in the superior colliculus. Science 284: 58-61, 1999.

Huerta MF, KRUBitzer LA, AND KAAs JH. Frontal eye field as defined by intracortical microstimulation in squirrel monkeys, owl monkeys, and macaque monkeys. II. Cortical connections. J Comp Neurol 265: 332-361, 1987.

Johnson PB, Ferraina S, Bianchi L, and Caminiti R. Cortical networks for visual reaching: physiological an anatomical organization of frontal and parietal lobe arm regions. Cereb Cortex 6: 102-119, 1996.

Jonides J, Smith EE, Koeppe RA, Awh E, Minoshima S, and Mintun MA. Spatial working memory in humans as revealed by PET. Nature 363: 623-625, 1993.

Keating EG, Gooley SG, Pratt SE, and Kelsey JE. Removing the superior colliculus silences eye movements normally evoked from stimulation of the parietal and occipital eye fields. Brain Res 269: 145-148, 1983.

KIM J-N AND SHADLEN MN. Neural correlates of a decision in the dorsolateral prefrontal cortex of the macaque. Nat Neurosci 2: 176-185, 1999.

KUNZLE H AND AKERT K. Efferent connections of cortical area 8 (frontal eye field) in Macaca fascicularis. A reinvestigation using the autoradiographic technique. J Comp Neurol 173: 147-164, 1977.

KURYLO DD AND SKAVENSKI AA. Eye movements elicited by electrical stimulation of area PG in the monkey. J Neurophysiol 65: 1243-1253, 1991.

LEMON R. Methods for neuronal recording in conscious animals. In: IBRO Handbook Series: Methods in the Neurosciences. New York: Wiley, 1984, vol. 4 , p. 95-102.

Li CS, MAZZONI P, AND ANDERSEn RA. Effect of reversible inactivation of macaque lateral intraparietal area on visual and memory saccades. $J$ Neurophysiol 81: 1827-1838, 1999.

LYNCH JC. Saccade initiation and latency deficits after combined lesions of the frontal and posterior eye fields in monkeys. J Neurophysiol 68: 1913-1916, 1992.

LYNCH JC, GRAYBIEL AM, AND LOBECK LJ. The differential projection of two cytoarchitectonic subregions of the inferior parietal lobule of macaque upon the deep layers of the superior colliculus. J Comp Neurol 235: 241-254, 1985.

Lynch JC, Mountcastle VB, Talbot WH, and Yin TCT. Parietal lobe mechanisms for directed visual attention. J Neurophysiol 40: 362-389, 1977.

MacPherson JM AND AldRIDGe JW. A quantitative method of computer analysis of spike train data collected from behaving animals. Brain Res 175: 183-187, 1979.

MAXWELL JS AND King WM. Dynamics and efficacy of saccade-facilitated vergence eye movements in monkeys. J Neurophysiol 68: 1248-1260, 1992. 
PARÉ M, FerRaina S, AND Wurtz RH. Visual motion signals from the ventral intraparietal area to the saccadic system. Soc Neurosci Abstr 25: 806, 1999.

PARÉ M AND WURTZ RH. Monkey posterior parietal cortex neurons antidromically activated from superior colliculus. J Neurophysiol 78: 3493-3497, 1997.

Paré M AND Wurtz RH. Progression in neuronal processing for saccadic eye movements from parietal cortex area LIP to superior colliculus. J Neurophysiol 85: 2545-2562, 2001.

PetiT L AND HaXBY JV. Functional anatomy of pursuit eye movements in humans as revealed by fMRI. J Neurophysiol 82: 463-471, 1999.

Petrides M AND PANDYA DN. Projections to the frontal cortex from the posterior parietal region in the rhesus monkey. J Comp Neurol 228: 105116, 1984.

PogGio GF AND Fischer B. Binocular interaction and depth sensitivity in striate and prestriate cortex of behaving rhesus monkey. J Neurophysiol 40: 1392-1405, 1977.

Quintana J AND Fuster JM. Mnemonic and predictive functions of cortical neurons in a memory task. Neuroreport 3: 721-724, 1992.

Richmond BJ, Optican LM, Podell M, AND Spitzer H. Temporal encoding of two-dimensional patterns by single units in primate inferior temporal cortex. I. Response characteristics. J Neurophysiol 57: 132-146, 1987.

ROBINSON DA AND FUCHS AF. Eye movements evoked by stimulation of frontal eye fields. J Neurophysiol 32: 637-648, 1969.

SCHALl JD. Visuomotor areas of the frontal lobe. In: Cerebral Cortex, edited by Rockland K, Kaas JH, and Peters A. New York: Plenum, 1997, p. 527-638.

Schall JD, Morel A, King DJ, AND Bullier J. Topography of visual cortex connections with frontal eye field in macaque: convergence and segregation of processing streams. J Neurosci 15: 4464-4487, 1995.

SChiller PH, Sandell JH, AND Maunsell JHR. The effect of frontal eye field and superior colliculus lesions on saccadic latencies in the rhesus monkey. J Neurophysiol 57: 1033-1049, 1987.

SEgraves MA AND Goldberg ME. Functional properties of corticotectal neurons in the monkey's frontal eye field. J Neurophysiol 58: 1387-1419, 1987.

SELEMON LD AND GoldMAN-RAKIC PS. Common cortical and subcorticl targets of the dorsolateral prefrontal and posterior parietal cortices in the rhesus monkey: evidence for a distributed neural network subserving spatially guided behavior. J Neurosci 8: 4049-4068, 1988.
Shadlen MN AND Newsome WT. Motion perception: seeing and deciding. Proc Natl Acad Sci USA 93: 628-633, 1996.

Shibutani H, SaKata H, AND HyvarinEn J. Saccades and blinking evoked by microstimulation of the posterior parietal association cortex of the monkey. Exp Brain Res 55: 1-8, 1984.

SOMMER MA AND TEHOVNIK EJ. Reversible inactivation of macaque frontal eye field. Exp Brain Res 116: 229-249, 1997.

SOMMER MA AND WuRTZ RH. Composition and topographic organization of signals sent from the frontal eye field to the superior colliculus. J Neurophysiol 83: 1979-2001, 2000.

SOMMER MA AND WURTz RH. Frontal eye field sends delay activity related to movement, memory, and vision to the superior colliculus. J Neurophysiol 85: 1673-1685, 2001.

SPARKS DL AND HARTwiCH-Young R. The neurobiology of saccadic eye movements. The deep layers of the superior colliculus. Rev Oculomot Res 3: 213-256, 1989.

Stanton GB, Bruce CJ, And Goldberg ME. Topography of projections to posterior cortical areas from the macaque frontal eye fields. J Comp Neurol 353: 291-305, 1995.

Swadlow HA, Rosene DL, AND WAXMAn SG. Characteristics of interhemispheric impulse conduction between prelunate gyri of the rhesus monkey. Exp Brain Res 33: 455-467, 1978.

Sweeney JA, Mintun MA, Kwee S, Wiseman MB, Brown DL, RosenberG DR, AND CARL JR. Positron emission tomography study of voluntary saccadic eye movements and spatial working memory. J Neurophysiol 75: 454-468, 1996.

THIER P AND ANDERSEN RA. Electrical microstimulation distinguishes distinct saccade-related areas in the posterior parietal cortex. J Neurophysiol 80: 1713-1735, 1998.

TIAN JR AND LyNCH JC. Corticocortical input to the smooth and saccadic eye movement subregions of the frontal eye field in Cebus monkeys. J Neurophysiol 76: 2754-1771, 1996.

TURnER RS AND DeLong MR. Corticostriatal activity in primary motor cortex of the macaque. J Neurosci 20: 7096-7108, 2000.

Wurtz RH, Sommer MA, Paré M, and Ferraina S. Signal transformations from cerebral cortex to superior colliculus for the generation of saccades. Vision Res 41: 3399-3412, 2001.

ZeE DS, FitzGibBon EJ, AND Optican LM. Saccade-vergence interactions in humans. J Neurophysiol 68: 1624-1641, 1992. 